\title{
ИНТЕГРАЦИОННАЯ ОРГАНИЗАЦИЯ \\ КАК ФОРМА МЕЖДУНАРОДНОГО СОТРУДНИЧЕСТВА \\ В ЦЕЛЯХ РЕАЛИЗАЦИИ ПОВЕСТКИ 2030: ТЕОРЕТИКО-ФУНКЦИОНАЛЬНЫЕ АСПЕКТЫ
}

\author{
О. Н. ЛЕШЕНЮК \\ Белорусский государственный университет, \\ Минск, Республика Беларусь
}

Аннотация. Данная статья посвящена теоретико-функциональным аспектам деятельности интеграционной организации как формы международного сотрудничества, основной задачей которой является имплементация Повестки 2030, озвученной на Саммите ООН в 2015 г. Автор рассматривает различные подходы к изучению интеграционных организаций, выделяет их функции: мониторинговую, регулирующую, рекомендательную, информирующую, аналитическую, стимулирующую, организационно-координирующую. Основной целью любой интеграционной структуры является достижение целей устойчивого развития и обеспечение устойчивости государств-членов и самой интеграции.

Автор делает вывод, что интеграционные организации образуют особую группу международных структур. Они создаются либо в качестве органов международных межправительственных организаций и межгосударственных объединений, либо в качестве межгосударственных договорных органов, в качестве конвенционных органов, либо, в отдельных случаях, в качестве самостоятельных международных организаций. В заключении делается вывод о том, что перед любой интеграцией стоит единая общая цель - достижение устойчивости ее членов и самой интеграционной структуры.

Ключевые слова: интеграционная организация; Повестка 2030; ООН; цели устойчивого развития; интеграция; форма международного сотрудничества.

Образец цитирования: Лешенюк $O$. . Интеграционная организация как форма международного сотрудничества в целях реализации повестки 2030: теоретико-функциональные аспекты // Актуальные проблемы международных отношений и глобального развития. Минск, 2021. Вып. 9. С. 227-241. https://doi.org/10.33581/2311-9470-2021-9-227-241

Введение. В научно-академической литературе отсутствует строгий и единый подход к интерпретации термина «интеграционная организация». Но тем не менее авторы не оставляют попыток прийти к единому знаменателю и разработать общее понятие. Интеграция может происходить совершенно в любых сферах - экономической, политической, социальной, как на межгосударственном, так и на 
уровне отдельно взятого предприятия. Различают также поверхностную интеграцию (затрагивающую только рыночную сферу) и глубокую интеграцию (проявляющуюся в сфере производства) [1, с. 164]. В этой связи появились понятия, описывающие интеграцию с точки зрения различных сфер жизни общества. К примеру, под экономической интеграцией понимается наивысшая ступень интернационализации, когда нарастающая экономическая взаимозависимость двух или нескольких стран переходит в сращивание национальных рынков товаров, услуг, капиталов и рабочей силы и формирование целостного рыночного пространства с единой валютно-финансовой системой, единой правовой системой и теснейшей координацией внутри- и внешнеэкономической политики соответствующих государств [2, с. 26]. Под политической интеграцией стоит понимать процесс сближения двух или более политических структур, направленный в сторону сотрудничества, в более узком смысле это формирование некоторого целостного комплекса политических систем на межгосударственном уровне [3, с. 6].

Методологическая основа. В соответствии с принципами социологического подхода интеграционные организации можно рассмотреть в качестве особой разновидности международных организационных структур, обладающих характеристиками одновременно межправительственных органов и собственно организаций [4, с. 81]. Интеграционные организации рассматриваются как отдельный объект социологических исследований в ряде отечественных работ в области социологии, международных отношений и мировой политики: А. П. Цыганков, П. А. Цыганков, А. Е. Кутейников, Е. И. Москальчук, а также значительно превосходящих по количеству работах зарубежных авторов: Э. Хаас, М. Алберт, М. Кох, М. Радсен, М. Хирш, К. Альтер, М. Барнетт, М. Финнемор, Дж. Миршаймер, Дж. Мейер, А. Этциони, П. Димаггио, В. Пауэл, Н. Брунсон, Б. Зангл и др.

Как правило, научные исследования интеграционных организаций лежат в области политических, юридических, экономических и социальных исследований. С точки зрения юридической науки рассматривается ряд вопросов, связанный с проблемами международноправовой ответственности, интерпретации положений международных договоров [5, с. 25; 6, с. 70] правовых принципов: принципа пропорциональности при ограничении того или иного права индивида [7, c. 215], субсидиарности и свободы усмотрения [8, с. 5; 9, с. 705], формирования правовых концепций, например, религиозной свободы 
[10, с. 9], наднациональности [11, с. 10], имплементации международно-правовых норм в национальные правовые системы [12, с. 205] правовых последствий имплементации норм, использования правовых принципов национальными судами [13, с. 383; 14, с. 144].

Политология решает вопросы, связанные с изучением самого интеграционного концепта [15, с. 119]. Труды Р. Натана и С. Хоффмана $[16$, с. 34], А. Спинелли [17, с. 11], Д. Элейзер [18, с. 106], А. Этциони $[19$, с. 25] заложили теоретическую базу для изучения интеграционных процессов, устанавливать закономерности их построения. Исследования рассматривают интеграцию как правовой и политический институт, дополняющий национальные системы [20, с. 64].

Социологическая наука в настоящее время сконцентрирована на исследовании функционирования социальных институтов [21, с. 4], их влияние на некоммерческие организации, социальных и политических процессах распространения норм и ценностей, противоречиях интеграционных объединений как элементов политической подсистемы [22, с. 4], тенденциях реформирования институционального дизайна интеграций. Отдельным направлением социологической науки является исследование эффективности интеграционных организаций [23, с. 10]. Еще одним примером социологического подхода к изучению интеграции является исследование интеграционной организации как бюрократии, взаимодействующей с иными организациями в качестве третьих сторон [24, с. 156]. Исследования интеграционных организаций сконцентрированы на тех социальных последствиях, на которые оказывает деятельность этих организаций [25, с. 13].

В современных исследованиях интеграционных выделяются четыре основных направления. Первое направление предполагает исследование истории формирования интеграций. Второе предполагает изучение действий организаций в связи с, или по отношению к отдельным государствам. Третье направление связано с интеграцией как учреждением, содействующим развитию прав человека, гражданского общества. В данном направлении поднимаются вопросы о природе интеграции, исторической памяти, о соотношении международно-правовых норм и национального законодательства. Сюда относятся и исследования, направленные на общий вклад деятельности интеграций в развитие дипломатии, экономического и политического сотрудничества, прав человека на международном уровне, гражданского общества, правозащитной деятельности. В отечественной науке 
подобной тематике посвящены работы А. Х. Абашидзе [26, с. 5], Е. С. Алисиевич [27, с. 29]

Еще одно направление исследований включает работы, посвященные прагматике функционирования интеграции, реформам. Некоторая часть этих исследований основана на сравнении функционирования интеграционных образований с подобными организациями в Европе и т. д. Рассматриваются вопросы институционального взаимодействия с международными организациями и их органами.

Поставленные в научных исследованиях вопросы взаимозависимы. Систематизация исследований международных организаций показывает, что в теоретических исследованиях широко используются концепции бюрократии и лидерства М. Вебера [28, с. 307; 29, с. 699; 30, с. 205], социального конструирования реальности П. Бергера и Т. Лукманна [31, с. 130], социальной системы и принятия решений в организациях Н. Луманна [32, с. 165], открытой системы [33, с. 207; 34, с. 147], функциональной дифференциации [35, с. 100] организационной автономности [36, с. 315], системы мирового общества [37, с. 49]. Однако далеко не все из них применимы к анализу интеграционных организаций с точки зрения концепции устойчивого развития.

В этих целях может быть применена теория функциональной дифференциации, в рамках которой интеграционное объединение будет рассматриваться как состояние социальной структуры и как процесс генезиса различных видов деятельности, ролей и социальных групп, нацеленный на выполнение функций, обеспечивающий устойчивость этой системы.

Подобный методологический ход осуществлен в концепции «мировых организаций как открытых систем» немецкого социолога M. Коха [38, с. 16]. В данной концепции внутренняя структура организации представлена формальными процедурами и неформальными процессами, протекающими в международной организации [38, с. 20]. М. Кох изучал социальные группы, влияющие на принятие решений в международных организациях. Подобные исследования целесообразно дополнить с целью их применения в эмпирических исследованиях интеграционных организаций, особенно с точки зрения принципов государственного управления и принятия решений в рамках Повестки 2030 каждого государства-члена интеграционного объединения.

Результаты исследования. Авторский подход к анализу интеграционной структуры основан на изучении этой организации, целью которой является достижение и реализация Повестки 2030. А это 
подразумевает и анализ протекающих процессов, взаимодействия интеграционной организации с другими международными и национальными организациями, распространения организацией норм и ценностей $[39$, с. 21].

В соответствии с «принципом понимания» М. Вебера «Такие понятия, как «государство», «товарищество», «феодализм» и другие, обозначают категории определенного рода совместных действий людей. Ввиду того, что любое индивидуальное действие, согласно концепции М. Вебера, осуществляется через «ориентацию на другого» [40, с. 68], оно носит характер социального: совместные действия людей образовывают социальные союзы и поддерживают социальный порядок.

Исходя из концепции формальной рациональности М. Вебера, международные интеграционные организации - бюрократии, результат постепенной рационализации политики. Конечным результатом постепенной рационализации обществ является распад ценностного порядка в современных обществах [40, с. 283]. Интеграционная организация - яркий пример бюрократии как чистого типа легального господства [40, с. 81]. В бюрократии такого рода подчиняются установленным законам в максимально возможном соответствии с формально-правовым началом. Управляет бюрократией «штаб управления» - группа специалистов, обладающих специальным образованием и компетенцией [40, с. 65].

Изучая интеграционное объединение необходимо принимать во внимание положения социологии организаций. Организация представляет собой социальный объект, состоящий из сети отношений, направляющий и регулирующий действия групп индивидов в соответствии с заранее определенными целями [41, с. 412]. В случае интеграций направляющую роль играют государства, представленный группами индивидов. В социологии организаций выделяется два подхода. Первый понимает организации как «рациональные системы», второй - как «социальные системы» [42, с. 400]. Основными структурными характеристиками организаций являются: 1) целеполагание; 2) степень формализации [41, с. 312].

Интеграционные организации обладают крайне высокой степенью формализации, с рутинизированной процедурой смены кадров, с четким распределением обязанностей. Однако если в традиционной организации основной значимой единицей является индивид, в интеграционной организации ключевым игроком выступает государство. 
В отношении степени формализации интеграционные организации являются рациональными системами. Сотрудники этих организаций представляют различающиеся государства, а иногда и различные культуры, языковые коды. По отношению к ним справедливо высказывание Р. Мертона: «... формализация определяет взаимодействие сотрудников в офисах вне зависимости от их (возможно враждебного) личного отношения друг к другу» [43, с. 195].

Социальная структура организации включает формальную и неформальную структуру [41, с. 315]. Каждая интеграционная организация обладает формальной и неформальной структурой, однако, степень ее формализации значительно выше, чем в любой другой организации. Это обусловлено международным характером таких организаций. Социальная структура организации представляет собой формальную структуру с подразделениями, формальными правилами и процедурами и неформальную структуру, включающие социальные нормы, ценности, паттерны поведения и коммуникации [41, с. 60]. Основными элементами в социальной структуре являются государства-члены. В этой связи интеграционная организация рациональное или аффективное [44, с. 140] поведение, взаимодействие в группе и коллективные представления в виде ценностей, убеждений и идей [45, с. 273] уже приписываются государствам-членам, как социальным общностям.

Интеграционные организации различаются по направлениям, целям и задачам, правовым основаниям деятельности. Однако авторы сходятся во мнении, что интеграция представляет собой единую систему, в основе которой лежит сближение или слияние нескольких систем. В данном диссертационном исследовании, посвященном политическим проблемам международных отношений, мы будем исходить из той мысли, что интеграция представляет собой форму международного сотрудничества, которая предполагает объединение сил двух или нескольких государств в целях решения задач по определенному направлению и согласимся с определением французских ученых П. Гонидека и Р. Шарвэна: «Интеграция - это одновременно процесс и состояние, имеющее тенденцию заменить раздробленные международные отношения, состоящие из независимых единиц, новыми более или менее широкими объединениями, наделенными минимальными полномочиями решений либо в одной или нескольких определенных областях, либо во всех областях, которые входят в компетенцию базовых единиц» [46, с. 35]. 
Интеграционные организации представляют собой и полноценные международные организации, действующие в рамках институциональной модели (в рамках подписанного государствами договора), и формирования и без институционального оформления, что обычно складывается на базе тесной экономической взаимозависимости. С нашей точки зрения основная функциональная задача любой интеграции - обеспечить устойчивое развитие государств-членов. Такой подход к рассмотрению интеграционных объединений позволяет рассматривать действия государств в формировании внешней политики сквозь призму Повестки 2030, предложенной Генеральной Ассамблеей $\mathrm{OOH}$ в 2015 г.

С точки зрения международного права и в соответствии с Уставом ООН одной из задач любых международных структур и, в целом, системы мировой политики является разрешение международных споров мирными средствами [47, с. 120]. Одним из механизмов достижения этой цели является двусторонняя и многостороння дипломатия, поэтому создание и координирование интеграционных процессов не может осуществляться без дипломатических переговоров. В этих же целях задействуются и специальные договорные органы [48, с. 220], судебные органы, механизмы региональной системы защиты прав человека $[49$, с. 80$]$ и др.

Интеграционные организации создаются для разрешения и предотвращения конфликтов и споров. Российский ученый Л. М. Камаровский находил целесообразным для предотвращения войн создание общего международного суда и специальных органов еще в 1881 г. [50, с. 46]. Ту же идею продолжил В. В. Кипарский в 1899 г. [51, с. 51], показавший на примере суда, что международная организация как постоянно заседающий орган представляет собой гибрид инструмента разрешения международных конфликтов и споров и постоянно действующей организации со своим персоналом, ценностями, нормами и организационной культурой. Таким образом, в настоящей работе под интеграционной организацией понимается постоянно действующая организация, учрежденная международным договором и функционирующая с целью реализации Повестки ООН 2030.

Интеграционные организации образуют особую группу международных структур. Они создаются либо в качестве органов международных межправительственных организаций и межгосударственных объединений (МПА СНГ), либо в качестве межгосударственных договорных органов (ОДКБ), в качестве конвенционных органов (Ев- 
ропейский суд по правам человека - интеграция в области международного права), либо, в отдельных случаях, в качестве самостоятельных международных организаций.

Цели интеграционных объединений и организаций варьируются в зависимости от сферы их компетенций, однако стоит выделить одну общую задачу интеграции - обеспечить устойчивость развития самой интеграции, в целом, и каждого государства - члена, в частности.

Интеграционной организации присущи следующие функции:

- мониторинговая - наблюдение за состоянием проблемы, для решения которой они созданы;

· регулирующая - призвана оказать содействие в обеспечении определенной стабильности в регионе, помощь отдельным странам в поисках выхода из кризисной ситуации, регулировать споры, возникающие между государствами, посредством рекомендательных решений на основании международно-правовых норм;

- рекомендательная - разработка рекомендаций, программ действий, дорожных карт;

· информирующая - служит дискуссионной площадкой для различных уровней власти;

- аналитическая - сбор и анализ данных о тенденциях развития региона;

- стимулирующая - развитие проектов для укрепления различных сфер интересов государств-членов и самой интеграции;

- организационно-координирующая - согласование и координация политики различных государств.

Интеграционные организации, как правило, учреждаются международным договором. Передача ряда функций в виде мандата от государств заложена в тексте договора. Интеграционные организации могут характеризоваться надгосударственностью и автономностью в решении некоторых задач, однако такая автономность зависит от степени и глубины интеграции.

Интеграционные объединения постсоветского пространства прошли долгий путь формирования, пока сложно говорить, что они могут характеризоваться автономностью и наднациональностью, но есть тенденция к постепенному развитию, изучению мирового и накоплению собственного опыта. В ходе развития интеграционных образований возникают новые организационные задачи, например, обеспечение информационной безопасности, реализация целей устойчивого развития и др. Расширение целей и задач вызывает 
усложнение структуры интеграционных объединений: увеличивается количество участников уставных документов, возникают «новые» организационные формы деятельности, расширяются возможности реформирования данных организаций, увеличивается количество сотрудников, разрабатываются рейтинговые системы оценки деятельности и т.д.

В качестве примера современных процессов в этой области помимо принятия новых внутренних правил процедуры, реформирования уставных документов стоит упомянуть создание дорожных карт по развитию интеграции (подписание пакета интеграционных дорожных карт Беларусью и Россией осенью 2021 г., к примеру). В дополнение ко всему процесс характеризуется вовлечением других межправительственных организаций в качестве «бенефициаров», иных интеграционных организаций, отдельных групп международных экспертов [52, с. 28-35].

Об указанных тенденциях также свидетельствует увеличение бюджетов интеграционных организаций. Так, общий планируемый бюджет Союзного государства в 2017 г. - 6714 799,2 тыс. российских рублей, в 2018 - 6925 055,3 тыс. российских рублей, в 2019 составлял 7245 026,6 тыс. российских рублей, в 2020 г. составлял 5521 544,9 тыс. российских рублей, в 2021 г. - 4715 153,3 тыс. рос. руб ${ }^{1}$. Необходимо отметить, что последние 2 года финансирование сократилось предположительно из-за пандемии в связи со снижением количества мероприятий.

Заключение. Таким образом, необходимо отметить, что процессы возникновения и реформирования интеграционных организаций постсоветского пространства с 1990-х гг. протекали в условиях доминирования мягкой и жесткой силы США и стран Западной Европы. Выделим следующие типы интеграционных организаций:

1) конвенционные и договорные органы в области прав человека (Суд Союзного государства, суд ЕАЭС);

2) региональных организации экономической интеграции (зона свободной торговли, таможенной союз, органы ЕЭК);

3) политическая интеграция (Союзное Государство);

4) специальные интеграционные объединения (ОДКБ).

\footnotetext{
${ }^{1}$ Декрет «О бюджете Союзного государства на 2021 год» от 16 марта 2021 г. №2 // Высший государственный совет союзного государства [Электронный pecypc]. URL: https://www.post komsg.com/budget/download.php?f=/upload/iblock/aee/Dekret-2-budget-2021.pdf (дата обращения: 20.08.2021).
} 
Функционирование интеграций в том виде, в котором они предстают сегодня, является результатом поиска рынков сбыта, ответом на внешние угрозы, санкции и способствует продвижению принципа патриотизма. Как межправительственные органы, созданные по воле государств, интеграционные организации служат достижению целей, определенных их учредителями. Однако перед любой интеграцией стоит единая общая цель - достижение устойчивости ее членов и самой интеграционной структуры.

\section{Библиографический список}

1. Костюнина Г. М., Интеграционные процессы в западном полушарии / Г.М. Костюнина ; Моск. гос. ин-т междунар. отношений (ун-т) МИД России, каф. междунар. экон. Отношений и внешнеэкон. связей — М. : МГИМО_Университет, 2013. — 318 с.

2. Шишков, Ю.В. Интеграционные процессы на пороге XXI века. Почему не интегрируются страны СНГ// Ю.В.Шишков. М., НП «ІІІ тысячелетие», 2001. 480 с.

3. Барановский В. Г. Политическая интеграция в Западной Европе. Некоторые вопросы теории и практики. М.: «Наука», 1983. 264 с.

4. Кутейников A. E. Международные межправительственные организации как особый класс организаций // Социологические исследования. 2011. № 11. С. 81-82.

5. Брусницын Л. В. Значение решений ЕСПЧ для национального уголовного судопроизводства и проблемы их учета в государствах - членах Совета Европы (К реформе Конвенции о защите прав человека и основных свобод) // Государство и право. 2013. № 2. С. 25-31.

6. Сальвиа М. Размышления об аксиологическом подходе в практике Европейского суда по правам человека // Сравнительное конституционное обозрение. 2012. № 5 (90). С. 70-79.

7. Dolzhikov A. The European Court of Human Rights on the principle of proportionality in "Russian" cases // Teise. 2012. № 82. P. 215-224.

8. Christoffersen J. Individual and Constitutional Justice: Can the Power of Adjudication be Reversed? // Christoffersen J., Madsen M. (Eds.) The European Court of Human Rights between Law and Politics. Oxford: Oxford University Press, 2011.

9. Letsas G. Two Concepts of the Margin of Appreciation // Oxford Journal of Legal Studies. 2006. Vol. 26. Iss. 4. P. 705-736.

10. Bhuta N. Two concepts of Religious Freedom in the European Court of Human Rights // South Atlantic Quaterly. 2013. Vol. 113. No. 1. P. 9-35.

11. Марусин И. С. Международные уголовные судебные учреждения: судоустройство и судопроизводство. Санкт-Петербург: СПбГУ, 2004. 223 с.

12. Липкина Н. Н. Правомерность вмешательства в осуществление прав и свобод, гарантируемых Конвенцией о защите прав человека и основных свобод 1950 года: практика Европейского суда по правам человека // Вестник Саратовской государственной академии права. 2008. № 1(59). C. 205-208.

13. Зимненко Б. Л. Международное право и правовая система Российской Федерации. Особенная часть. М.: Статут, 2010. 543 с.

14. Hennette-Vauchez S. Constitutional v International? When Unified Reformatory Rationales Mismatch the Plural Paths of Legitimacy of ECHR Law // Christoffersen J., Madsen M. (Eds.) The European Court of Human Rights between Law and Politics. Oxford: Oxford University Press, 2011. P. 144-163.

15. Mitrany D. The prospect of integration: federal or functional // Journal of Common Market Studies. 1965. Vol. 4. p. 119-149.

16. Натан Р. П. Хоффманн Э. П. Современный федерализм // Международная жизнь. 1991. №4. C. 34-49. 
17. Spinelli A., Rossi E. The Ventotene Manifesto. Ventotene: Altiero Spinelli Institute for Federalist Studies, 1988. 68 p.

18. Элейзер Д. Д. Сравнительный федерализм // Полис. 1995. № 5. С. 106-115.

19. Etzioni A. Political Unification Revisited: On Building Supernational Communities. Lanham: Lexington Books, 2001. 346 p.

20. Симонова A. E. Становление механизма защиты прав человека и свобод человека Европейским судом по правам человека // Вестник экономической безопасности. 2017. № 3. С. 64-66.

21. Тимофеев M. Европейский суд по правам человека и непрекращающаяся борьба с Левиафаном // Международное правосудие. 2012. № 1(2). С. 4-6.

22. Keller H. Sweet A. A Europe of Rights: the Impact of the ECHR on National Legal Systems. Oxford: Oxford University Press, 2008. 672 p.

23. Alter $K$. The New Terrain of International Law: Courts, Politics, Rights. Princeton: Princeton University Press, 2014. $450 \mathrm{p}$.

24. Bürli N. Third-party Interventions before the European Court of Human Rights: amicus curiae, member-state and third-party interventions. Cambridge: Intersentia, 2017. $214 \mathrm{c}$.

25. Черников П. Г. Как оценить ООН? О некоторых методах анализа результативности и эффективности международных организаций. М.: Р.Валент, 2005. 183 с.

26. Абашидзе A. Х., Алисиевич E. C. 10 лет участия России в Конвенции Совета Европы по правам человека: значение для российского законодательства и правоприменительной практики // Законы России: опыт, анализ, практика. 2008. № 12. С. 6-14.

27. Алисиевич $E$. C. Поощрение и защита прав уязвимых групп в международном праве. М.: РУДН, 2012. $225 \mathrm{c}$.

28. Weber M. Wirtschaft und Gesellschaft: Grundriss der verstehenden Soziologie.Tübingen: Mohr. $1922.942 \mathrm{c}$.

29. Barnett, M., Finnemore, M. The Politics, Power, and Pathologies of International Organizations // International Organization. 1999. Vol. 53. No. 4. P. 699-732.

30. Cox, R. The Executive Head: An Essay on Leadership in the ILO // International Organization. 1969. Vol. 23. No 2. P. 205-229.

31. Christiansen T., Jørgensen K., Wiener A. The Social Construction of Europe. London: Sage, 2001. $248 \mathrm{p}$.

32. Luhmann N. Organisationen // Küpper W., Ortmann G. (Eds.) Mikropolitik Rationalität, Macht und Spiele in Organisationen. Opladen: Westdeutscher Verlag, 1988. C. 165-185.

33. Weick, K. Sensemaking in Organizations. Thousand Oaks: Sage. 1995. 248 c.

34. DiMaggio P., Walter P. The Iron Cage Revisited: Institutional Isomorphism and Collective Rationality in Organizational Fields // American Sociological Review. 1983. Vol. 48. No. 2. P. 147-160.

35. Haas E. Beyond the Nation-State: Functionalism and International Organization. Stanford: Stanford University Press, 1964. P. 132.

36. Zacher M. The Secretary-General and the United Nations' Function of Peaceful Settlement // International Organization. 1966. Vol. 20. No 4. P. 737.

37. Albert M. A Theory of World Politics. Cambridge: Cambridge University Press, 2016. 278 p.

38. Koch $M$. Weltorganisationen. Ein (Re)Konzeptualisierungsvorschlag für internationale Organisationen // Zeitschrift für Internationale Beziehungen (ZIB). Vol. 21. No. 1. 2014. P. 5-38.

39. Dingwerth K., Kerwer D., Nölke A. Einleitung: InternationalePolitik und Organisationen // Dingwerth K. Kerwer D. Nölke A. (Eds.) Die Organisierte Welt: Internationale Beziehungen und Organisationsforschung.Baden-Baden. Nomos Verlag. 2009. P. 21-31.

40. Гайденко П. П., Давыдов Ю. Н. История и рациональность: социология Макса Вебера и веберовский ренессанс. М.: КомКнига, 2006. 367 с.

41. Scott R. Social Processes and Social Structures. New York: Stanford University Press, 1979. 412 p.

42. Gouldner A. Organizational analysis. // Merton R., Broom L., Cottrell L. (Eds.) Sociology today: Problems and prospects. NewYork: Harper Torchbook, 1959. P. 400-428.

43. Merton R. Social Theory and Social Structure. Glencoe: Free Press, 1957. 195 p. 
44. Parsons T. Some Afterthoughts on Gemeinschaft and Gesellschaft // Cahnman W. J. (Ed.) Ferdinand Tönnies: A New Evaluation. Leiden: Brill, 1973. P. 140-150.

45. Durkheim É. Représentations individuelles et représentations collectives // Revue de métaphysique et de morale. Tome VI. 1898. P. 273-302.

46. Gonidec P., Charvin R. Relations internationals. P. : Montchrestien, 1984. 435 p.

47. Тункин Г. И. Теория международного права. М.: Международные отношения, 1970. 342 с.

48. Солнцев $A$. M. Интеграционные международные органы как средство разрешения международных экологических споров // Вестник КГУ им. Н. А. Некрасова. № 3, 2015. С. 220-222.

49. Небратенко O. О. Международные региональные механизмы защиты прав человека // Юристь - Правоведъ. 2016. № 2 (76). С. 80-87.

50. Камаровский Л. О международном суде. М.: Тип. Т. Малинского, 1881. 542 с.

51. Кипарский B. B. О замене войны международным судом. Санкт-Петербург.: Паровая скороп. П. О. Яблонского, 1899. 48 с.

52. Boyashov A. Third Party Expertise in the European Court of Human Rights // Интеграционные процессы на евразийском пространстве: успехи, проблемы, перспективы. Санкт-Петербург: МИЭП, 2014. $151 \mathrm{c.}$

Дата поступления статьи: 09.09.2021.

Автор: Лешенюк Олег Николаевич - заместитель декана по международной деятельности, директор Центра международных исследований, соискатель кафедры международных отношений факультета международных отношений Белорусского государственного; e-mail: leshenyuk.oleg@gmail.com.

\title{
INTEGRATION ORGANIZATION AS A FORM OF INTERNATIONAL COOPERATION TO IMPLEMENT AGENDA 2030: THEORETICAL AND FUNCTIONAL ASPECTS
}

\author{
O. LESHENYUK \\ Belarusian State University, Minsk, Republic of Belarus
}

\begin{abstract}
This article is devoted to theoretical and functional aspects of the activities of integration organization as one of the forms of multilateral cooperation. The main function of integration organization is the implementation of the 2030 Agenda, announced at the UN Summit in 2015. The author integrates various approaches to the study of functions of integration organisations. The main goal of any integration structure is to achieve development goals and ensure the sustainability of the member states and the integration itself. The author concludes that integration structures form a special group of structural organizations. They are either intergovernmental organizations, or as independent international organizations. The functions of integration organization are monitoring, regulating, recommending, informing, analytical, stimulating, organizational and coordinating.

The functioning of integrations in the form they appear today is the result of a search for markets, a response to external threats, sanctions and contributes to the promotion of the principle of patriotism. As intergovernmental bodies created by the will of states, integration organizations serve to achieve the goals defined by their
\end{abstract}


founders. In conclusion, it is pointed out that any integration has a single common goal - to achieve the sustainability of its members and the integration structure itself.

Keywords: integration organization; Agenda 2030; UN; sustainable development goals; integration; form of international cooperation.

For citations: Leshenyuk O. (2021). Integratsionnaya organizatsiya kak forma mezhdunarodnogo sotrudnichestva $\mathrm{v}$ tselyakh realizatsii povestki 2030: teoretikofunktsional'nyye aspekty [Integration organization as a form of international cooperation to implement Agenda 2030: theoretical and functional aspects]. In: Actual problems of international relations and global development: collection of scientific papers. Minsk. Vol. 9, p. 227-241. https://doi.org/10.33581/2311-9470-2021-9-227-241

\section{References}

1. Kostjunina G. M., Integracionnye processy v zapadnom polusharii / G.M. Kostjunina ; Mosk. gos. in-t mezhdunar. otnoshenij (un-t) MID Rossii, kaf. mezhdunar. jekon. Otnoshenij i vneshnejekon. svjazej — M. : MGIMO_Universitet, 2013. — $318 \mathrm{~s}$.

2. Shishkov Ju.V. Integracionnye processy na poroge HH1 veka. Pochemu ne integrirujutsja strany SNG// Ju.V. Shishkov. M., NP "III tysjacheletie", 2001. 480 p.

3. Baranovskij V. G. 1983. Politicheskaja integracija v Zapadnoj Evrope. Nekotorye vopro-sy teorii i praktiki. M.: «Nauka», 1983. 264 p.

4. Kutejnikov A. E. Mezhdunarodnye mezhpravitel'stvennye organizacii kak osobyj klass organizacij // Sociologicheskie issledovanija. 2011. № 11. P. 81-82.

5. Brusnicyn L. V. Znachenie reshenij ESPCh dlja nacional'nogo ugolovnogo sudoproizvod-stva i problemy ih ucheta $v$ gosudarstvah - chlenah Soveta Evropy (K reforme Konvencii o zashhite prav cheloveka i osnovnyh svobod) // Gosudarstvo i pravo. 2013. № 2. P. 25-31.

6. Sal'via M. Razmyshlenija ob aksiologicheskom podhode v praktike Evropejskogo suda po pravam cheloveka // Sravnitel'noe konstitucionnoe obozrenie. 2012. № 5 (90). P. 70-79.

7. Dolzhikov A. The European Court of Human Rights on the principle of proportionality in "Russian” cases // Teise. 2012. № 82. P. 215-224.

8. Christoffersen J. Individual and Constitutional Justice: Can the Power of Adjudication be Reversed? // Christoffersen J., Madsen M. (Eds.) The European Court of Human Rights between Law and Politics. Oxford: Oxford University Press, 2011.

9. Letsas G. Two Concepts of the Margin of Appreciation // Oxford Journal of Legal Studies. 2006. Vol. 26. Iss. 4. P. 705-736.

10. Bhuta N. Two concepts of Religious Freedom in the European Court of Human Rights // South Atlantic Quaterly. 2013. Vol. 113. No. 1. P. 9-35.

11. Marusin I. S. Mezhdunarodnye ugolovnye sudebnye uchrezhdenija: sudoustrojstvo i sudoproizvodstvo. Sankt-Peterburg: SPbGU, 2004. 223 p.

12. Lipkina N. N. Pravomernost' vmeshatel'stva v osushhestvlenie prav i svobod, garanti-ruemyh Konvenciej o zashhite prav cheloveka i osnovnyh svobod 1950 goda: praktika Evro-pejskogo suda po pravam cheloveka // Vestnik Saratovskoj gosudarstvennoj akademii prava. 2008. № 1(59). S. 205-208.

13. Zimnenko B. L. Mezhdunarodnoe pravo i pravovaja sistema Rossijskoj Federacii. Osobennaja chast'. M.: Statut, 2010. 543 p.

14. Hennette-Vauchez S. Constitutional v International? When Unified Reformatory Rationales Mismatch the Plural Paths of Legitimacy of ECHR Law // Christoffersen J., Madsen M. (Eds.) The European Court of Human Rights between Law and Politics. Oxford: Oxford University Press, 2011. S. 144-163. 
15. Mitrany D. The prospect of integration: federal or functional. In: Journal of Common Market Studies. 1965. Vol. 4. p. 119-149.

16. Natan R. P. Hoffmann Je. P. Sovremennyj federalism. In: Mezhdunarodnaja zhizn'. 1991. №4. P. 34-49.

17. Spinelli A., Rossi E. The Ventotene Manifesto. Ventotene: Altiero Spinelli Institute for Federalist Studies, 1988. 68 p.

18. Jelejzer D. D. Sravnitel'nyj federalism. In: Polis. 1995. № 5. P. 106-115.

19. Etzioni A. Political Unification Revisited: On Building Supernational Communities. Lanham: Lexington Books, 2001. 346 p.

20. Simonova A. E. Stanovlenie mehanizma zashhity prav cheloveka i svobod cheloveka Evro-pejskim sudom po pravam cheloveka. In: Vestnik jekonomicheskoj bezopasnosti. 2017. № 3. P. 64-66.

21. Timofeev M. Evropejskij sud po pravam cheloveka i neprekrashhajushhajasja bor'ba s Leviafanom. In: Mezhdunarodnoe pravosudie. 2012. № 1(2). P. 4-6.

22. Keller H. Sweet A. A Europe of Rights: the Impact of the ECHR on National Legal Systems. Oxford: Oxford University Press, 2008. 672 p.

23. Alter K. The New Terrain of International Law: Courts, Politics, Rights. Princeton: Princeton University Press, 2014. 450 p.

24. Bürli N. Third-party Interventions before the European Court of Human Rights: amicus curiae, member-state and third-party interventions. Cambridge: Intersentia, 2017. 214 c.

25. Chernikov P. G. Kak ocenit' OON? O nekotoryh metodah analiza rezul'tativnosti i jeffektivnosti mezhdunarodnyh organizacij. M.: R.Valent, 2005. 183 c.

26. Abashidze A. H., Alisievich E. S. 10 let uchastija Rossii v Konvencii Soveta Evropy po pravam cheloveka: znachenie dlja rossijskogo zakonodatel'stva i pravoprimenitel'noj prak-tiki. In: Zakony Rossii: opyt, analiz, praktika. 2008. № 12. P. 6-14.

27. Alisievich E. S. Pooshhrenie i zashhita prav ujazvimyh grupp v mezhdunarodnom prave. M.: RUDN, , 2012. 225 p.

28. Weber M. Wirtschaft und Gesellschaft: Grundriss der verstehenden Soziologie.Tübingen: Mohr. 1922. $942 \mathrm{p}$.

29. Barnett M., Finnemore M. The Politics, Power, and Pathologies of International Organizations. In: International Organization. 1999. Vol. 53. No. 4. P. 699-732.

30. Cox R. The Executive Head: An Essay on Leadership in the ILO. In: International Organization. 1969. Vol. 23. No 2. P. 205-229.

31. Christiansen T., Jørgensen K., Wiener A. The Social Construction of Europe. London: Sage, 2001. 248 p.

32. Luhmann N. Organisationen // Küpper W., Ortmann G. (Eds.) Mikropolitik Rationalität, Macht und Spiele in Organisationen. Opladen: Westdeutscher Verlag, 1988. P. 165-185.

33. Weick K. Sensemaking in Organizations. Thousand Oaks: Sage. 1995. 248 p.

34. Di Maggio P., Walter P. The Iron Cage Revisited: Institutional Isomorphism and Collective Rationality in Organizational Fields. In: American Sociological Review. 1983. Vol. 48. No. 2. P. 147-160.

35. Haas E. Beyond the Nation-State: Functionalism and International Organization. Stanford: Stanford University Press, 1964. 132 p.

36. Zacher M. The Secretary-General and the United Nations' Function of Peaceful Settlement. In: International Organization. 1966. Vol. 20. No 4. P. 737.

37. Albert M. A Theory of World Politics. Cambridge: Cambridge University Press, 2016. S. 278.

38. Koch M. Weltorganisationen. Ein (Re)Konzeptualisierungsvorschlag für internationale Organisationen // Zeitschrift für Internationale Beziehungen (ZIB). Vol. 21. No. 1. 2014. P. 5-38.

39. Dingwerth K., Kerwer D., Nölke A. Einleitung: InternationalePolitik und Organisationen // Dingwerth K. Kerwer D. Nölke A. (Eds.) Die Organisierte Welt: Internationale Beziehungen und Organisationsforschung.Baden-Baden. Nomos Verlag. 2009. P. 21-31.

40. Gajdenko P. P., Davydov Ju. N. Istorija i racional'nost': sociologija Maksa Vebera i veberovskij renessans. M.: KomKniga, 2006. 367 c.

41. Scott R. Social Processes and Social Structures. New York: Stanford University Press, 1979. 412 p. 
42. Gouldner A. Organizational analysis. // Merton R., Broom L., Cottrell L. (Eds.) Sociology today: Problems and prospects. NewYork: Harper Torchbook, 1959. P. 400-428.

43. Merton R. Social Theory and Social Structure. Glencoe: Free Press, 1957. P. 195.

44. Parsons T. Some Afterthoughts on Gemeinschaft and Gesellschaft // Cahnman W. J. (Ed.) Ferdinand Tönnies: A New Evaluation. Leiden: Brill, 1973. P. 140-150.

45. Durkheim É. Représentations individuelles et représentations collectives In: Revue de métaphysique et de morale. Tome VI. 1898. P. 273-302.

46. Gonidec P., Charvin R. Relations internationals. P. : Montchrestien, 1984. P. 435.

47. Tunkin G. I. Teorija mezhdunarodnogo prava. M.: Mezhdunarodnye otnoshenija, 1970. 342 p.

48. Solncev A. M. Integracionnye mezhdunarodnye organy kak sredstvo razreshenija mezhdunarodnyh jekologicheskih sporov. In: Vestnik KGU im. N. A. Nekrasovaju. № 3, 2015. P. 220-222.

49. Nebratenko O. O. Mezhdunarodnye regional'nye mehanizmy zashhity prav cheloveka. In: Jurist - Pravoved. 2016. № 2 (76). P. 80-87.

50. Kamarovskij L. O mezhdunarodnom sude. M.: Tip. T. Malinskogo, 1881. 542 p.

51. Kiparskij V. V. O zamene vojny mezhdunarodnym sudom. Sankt-Peterburg.: Parovaja skorop. P. O. Jablonskogo, 1899. 48 p.

52. Boyashov A. Third Party Expertise in the European Court of Human Rights // Integracion-nye processy na evrazijskom prostranstve: uspehi, problemy, perspektivy. Sankt-Peterburg: MIJeP, 2014. $151 \mathrm{p}$.

Received: 09.09.2021.

About author: Leshenyuk Oleg - Deputy Dean for International Affairs, Head of the Center for International Studies, PhD candidate for the Department of International Relations, Faculty of International Relations, Belarusian State University; e-mail: leshenyuk.oleg@gmail.com. 